\title{
Imprinted Polymers: Versatile New Tools in Synthesis
}

\author{
M.J. Whitcombe, ${ }^{*}$ C. Alexander, ${ }^{\ddagger}$ E. N. Vulfson \\ BBSRC Institute of Food Research, Norwich Research Park, Colney, Norwich, NR4 7UA, UK \\ Tel +44 1603 255000; Fax +44 1603 507723; E-mail: michael.whitcombe@bbsrc.ac.uk \\ Received 28 March 2000
}

\begin{abstract}
The use of molecularly imprinted polymers in synthetic organic chemistry is reviewed. These materials are prepared in the presence of a template for which they carry a functional and stereochemical "memory" and can be likened to artificial antibodies or enzymes. Their unique properties have been exploited by the use of imprinted polymers as stereo- and regio-selective solid supports in condensation reactions and hydride reduction, as protecting groups in the acylation of polyols and as catalysts to enhance the rates of reactions as diverse a Diels-Alder reaction, an Aldol condensation, $\beta$-elimination, the benzisoxazole isomerization, transesterification and ester hydrolyses.
\end{abstract}

Key words: molecular imprinting, imprinted polymer, selectivity, chemical modification, synthesis

\section{$1 \quad$ Introduction}

The technique of molecular imprinting, in which a crosslinked polymer is assembled around a template, utilizing its interaction with functional monomers to create a recognition site, complementary in both shape and functionality to the original occupant, has become well established and many research groups are currently active in this field. ${ }^{1-11}$ A schematic diagram of the imprinting process is shown in Figure 1.

There have now been a number of examples illustrating the spectacular performance of imprinted polymers in a range of applications from chiral chromatographic separations ${ }^{12-14}$ to the binding of ligands with a specificity rivaling that of antibodies..$^{15-16}$ However, it is becoming clear that the versatility of the imprinting methodology can be exploited to generate polymers for uses beyond those involving simply the recognition or separation of small organic molecules. In particular, researchers have begun to explore the use of imprinted polymers in synthesis, with a view to creating novel and robust reactive supports, as "protecting groups" and catalysts. In this short review we focus on the above applications, and outline some recent work which has taken the field of imprinted polymers into the realms of organic, inorganic, and biomimetic chemistry.

\section{2 "Microreactors" for chiral synthesis}

The use of the imprinted recognition sites as potential chiral cavities for enantioselective synthesis was first described by the research groups of Shea ${ }^{17}$ and Neckers, ${ }^{18}$ and synthetic transformations including enantioselective protonation-deprotonation $^{19}$ and selective hydrolysis ${ }^{20}$ have also been carried out in imprinted sites. However, perhaps the most elegant early work in this area was due to Wulff and co-workers, who targeted their initial studies to $\mathrm{C}-\mathrm{C}$ bond formation in a biomimetic synthesis of $\alpha$ amino acids from glycine. ${ }^{21}$ The model system set out by Wulff involved alkylation of a polymer-bound glycine, present as an ester enolate. The synthetic scheme on which this is based is shown in Figure 2, in which the glycine-Schiff base (1) is deprotonated to the enolate (2) amenable to alkylation via appropriate routes (alkyl halide, aldol condensation, Michael addition) to give the substituted amino acids $\mathbf{3}, \mathbf{4}$ and 5 . a)

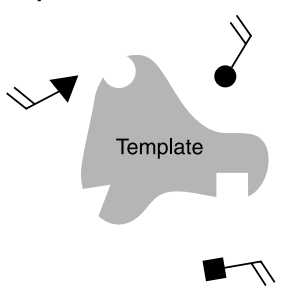

b)

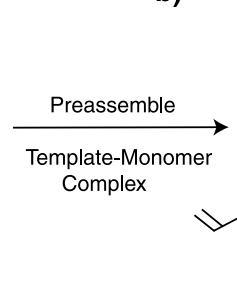

)

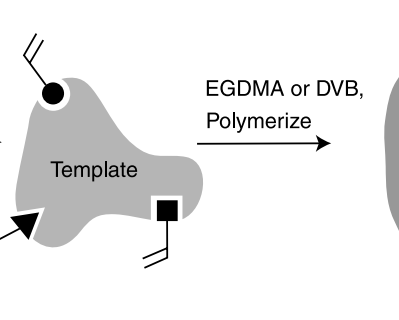

c)

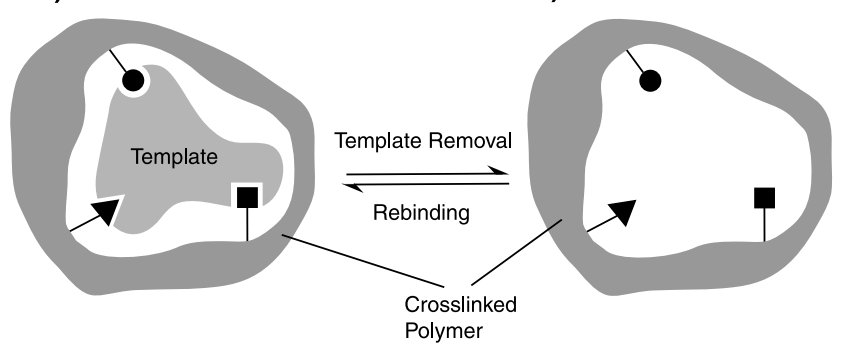

Figure 1 Schematic diagram of the molecular imprinting process: a) The template is mixed with vinyl monomers, selected to interact with functionality of the template. b) The template-monomer complex may be formed by covalent or non-covalent associations (or a mixture of both). c) The complex is co-polymerized with an excess of cross-linking monomer, ethyleneglycol dimethacrylate (EGDMA) or divinylbenzene (DVB) are typically used. The inclusion of a small amount of solvent ensures that the polymer structure is porous, allowing access to the sites within the polymer monolith. d) The polymer is usually ground to a powder for ease of handling and the template removed by solvent extraction or a chemical treatment. The sites created in the polymer are complementary in shape to the template and bear the functionality originally involved in complex formation, precisely arrange to interact with the template on rebinding. 


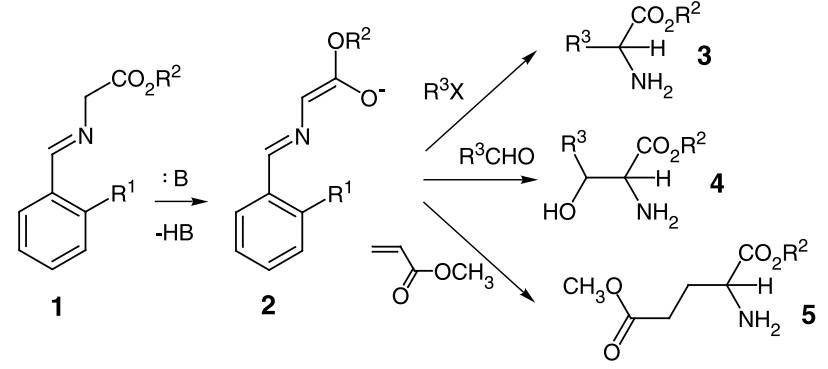

Figure 2 Synthetic scheme proposed by Wulff ${ }^{21}$ for the preparation of amino acid derivatives at a polymer binding site: The glycinebenzaldehyde derivative Schiff's base (1) can be deprotonated to the enolate (2) which can be reacted with an alkyl halide to form $\mathbf{3}$, undergo an aldol condensation to yield $\mathbf{4}$ or Michael addition (5).

In order to carry out such a process within an imprinted polymer binding site, the glycine derivative (1) was substituted by the polymerizable L-phenylalanine derivative
(6), such that the amino acid became fixed via a single Schiff-base linkage within a chiral recognition cavity. In addition, two further monomers were prepared to enable the amino acid derivatives to be bound additionally by the carboxyl function (7) or via the side chain of the corresponding L-DOPA derivative (8) as well as by the azomethine link (Figure 3).

These monomers were imprinted by copolymerization with divinylbenzene (DVB) or ethyleneglycol dimethacrylate (EGDMA) and the templates removed from the resultant polymers to yield binding sites with one or two points of attachment for glycine derivatives. The proposed alkylation scheme employing $\mathbf{8}$ as the template molecule is shown in Figure 4.

The binding of glycine (9) to the exposed recognition sites and subsequent deprotonation with lithium diisopropylamide (LDA) yielded an ester enolate where the enantiotopic methylene protons became diastereotopic in the

\section{Biographical Sketches}
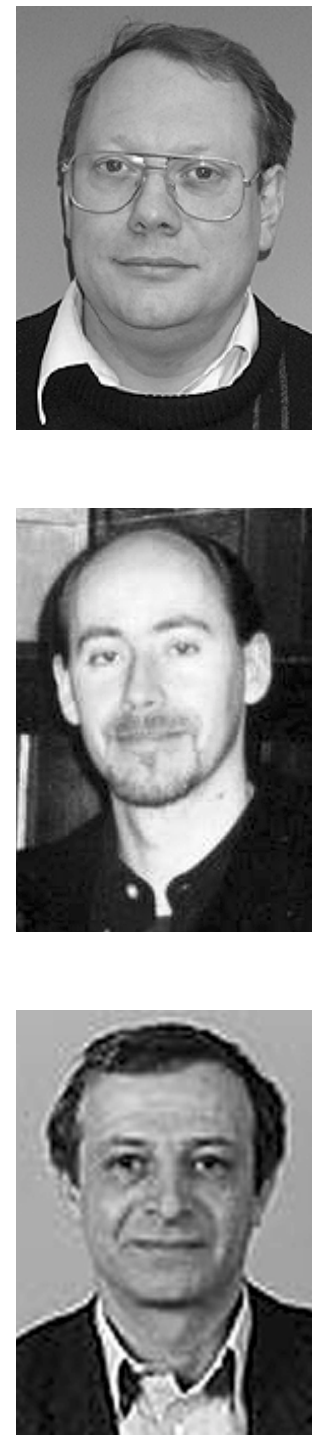

Michael Whitcombe graduated from Oxford University in 1980 and gained a $\mathrm{PhD}$ in organic chemistry from London University

Cameron Alexander studied Chemistry at the University of Durham, and stayed to undertake research with Professor Jim Feast, FRS, obtaining his PhD in 1990. Following post-doctoral work at the Melville Laboratory for Polymer Synthe-

\footnotetext{
Evgeny (Jenya) Vulfson graduated from Moscow State University in 1980 and gained his $\mathrm{PhD}$ in bio-organic chemistry in 1985 from the same University. In 1990 Dr Vulfson was appointed as a Head of Section
}

(1987). After spending 4 years as a post-doctoral research fellow at the Polymer Centre, University of Reading, Dr Whitcombe joined
IFR in 1992. His main interests include molecular recognition in synthetic and materials chemistry. sis, University of Cambridge, he joined the Macromolecular Science Department at IFR to work with Jenya Vulfson and Mike Whitcombe on molecular imprinting. Dr Alexander has recently been appointed to a Senior Lec- at the Institute of Food Research (IFR). Currently he is a Principal Senior Scientist at IFR, Norwich. Dr Vulfson has published more than 70 research papers. His current interests include the use of biocatalysts for the syn- thesis/modification natural products, applications of imprinted polymers in the food industry and biotechnology and "nutraceuticals". 
<smiles>C=Cc1ccc(O)c(/C=N/[C@H](Cc2ccccc2)C(=O)OC)c1</smiles>

6<smiles>C=Cc1ccc(C(OC(=O)[C@H](Cc2ccccc2)N=Cc2cc(C=C)ccc2O)c2ccc(C=C)cc2)cc1</smiles>

7<smiles>C=Cc1ccc(B2Oc3ccc(C[C@H](N=Cc4cc(C=C)ccc4O)C(=O)OC)cc3O2)cc1</smiles>

8

Figure 3 Templates for the preparation of amino acid "microreactors"21: based on L-phenylalanine, 6 and 7 or L-DOPA (8).

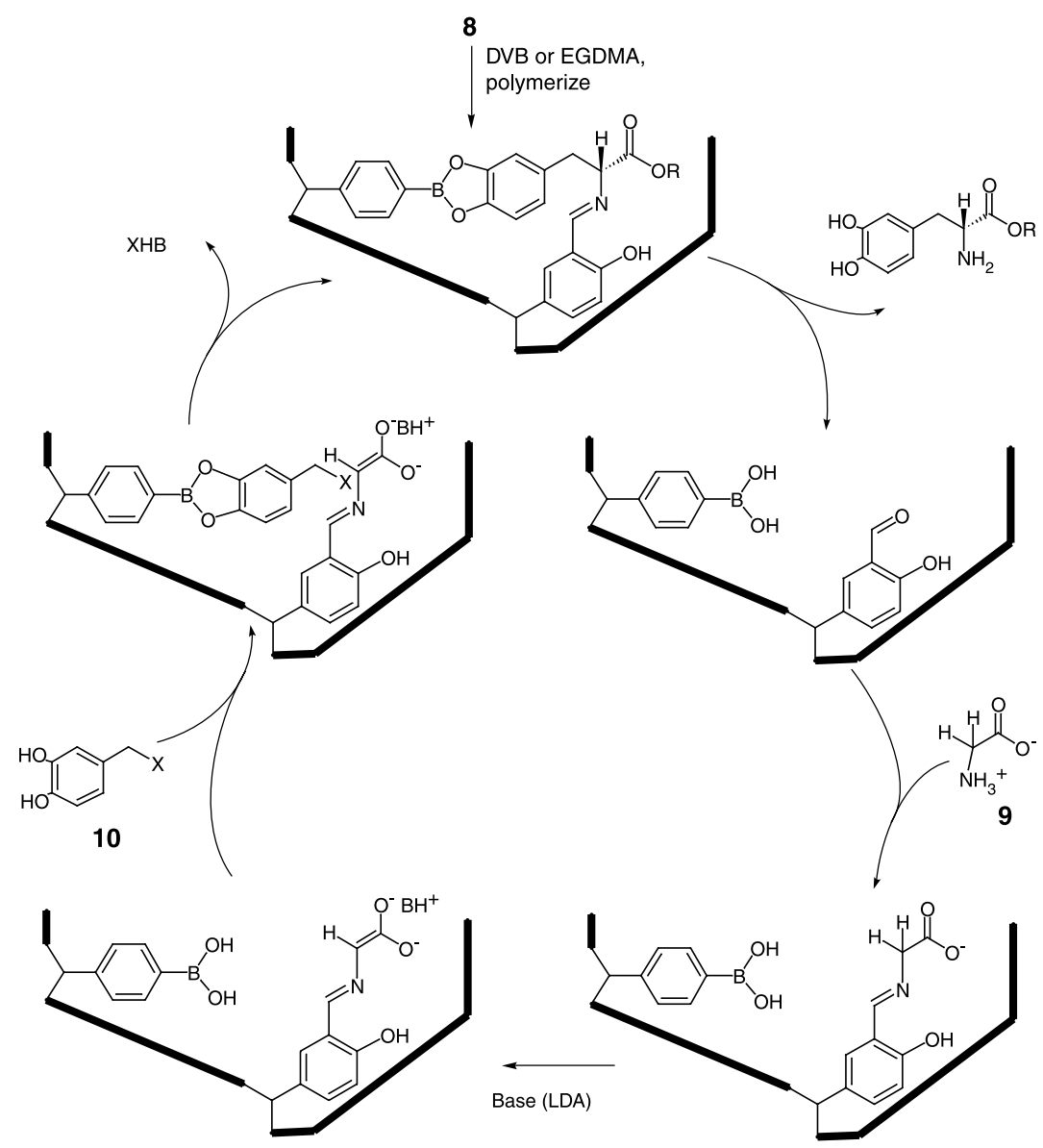

Figure 4 Synthetic scheme for the preparation of L-DOPA from glycine in polymer sites templated with $\mathbf{8}$. Asymmetric induction in the synthesis derives from the stereochemical memory of the template.

cavities. Esterification of the polymer-bound boronic acid group with a dihydroxybenzylic halide (10) enabled the placement of an alkylating agent in the correct position and orientation to react stereospecifically with the glycine ester enolate. In this way, the chiral environment set up by the imprinting process was instrumental in the asymmetric induction which occurred during alkylation. Although in practice the stability of 3,4-dihydroxybenzyl halides as alkylating agents proved too low to establish the efficacy of this particular synthesis, the same imprinted polymer was used to generate the chiral environment necessary to effect an aldol condensation in 36\% ee (Figure 5). In the latter case, the glycine ester enolate was fixed at a second point in the site by coordination to a metal centre, preventing rotation about the $\mathrm{C}-\mathrm{N}$ single bond. Removal of a proton from the enolate with DBU followed by reaction with acetaldehyde generated threonine and allo-threonine (11, 12), and the enantiomeric excess was postulated to arise 


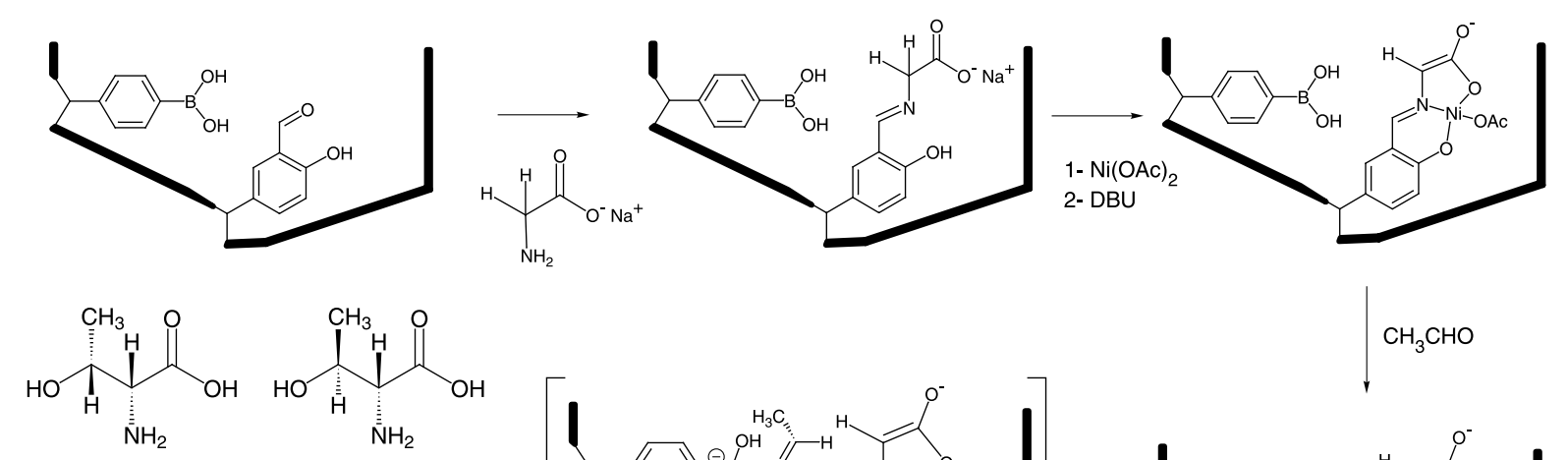<smiles>C[C@@H](O)[C@H](N)C(=O)O</smiles>

11<smiles>CC(O)C(N)C(=O)O</smiles>

12
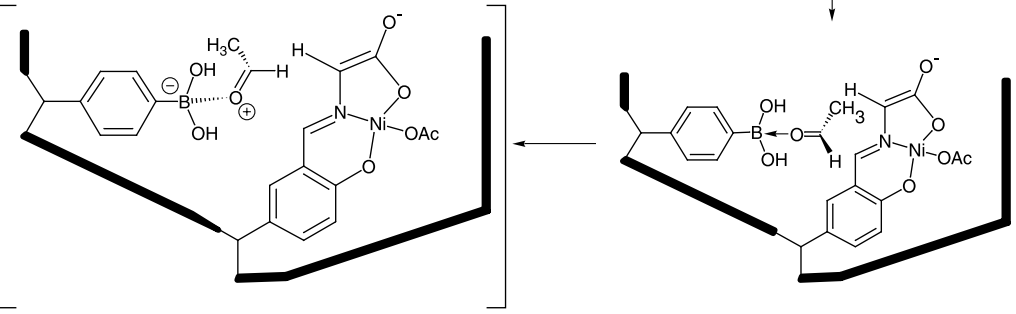

Figure 5 Aldol condensation carried out in the L-DOPA imprint site. Co-ordination to nickel prevents the glycine enolate from undergoing single bond rotation. In addition association of the attacking acetaldehyde with the electron deficient boron atom assists in directing its attack on the enolate. The resulting products, threonine (11) and allothreonine (12) are produced with substantial stereochemical control.
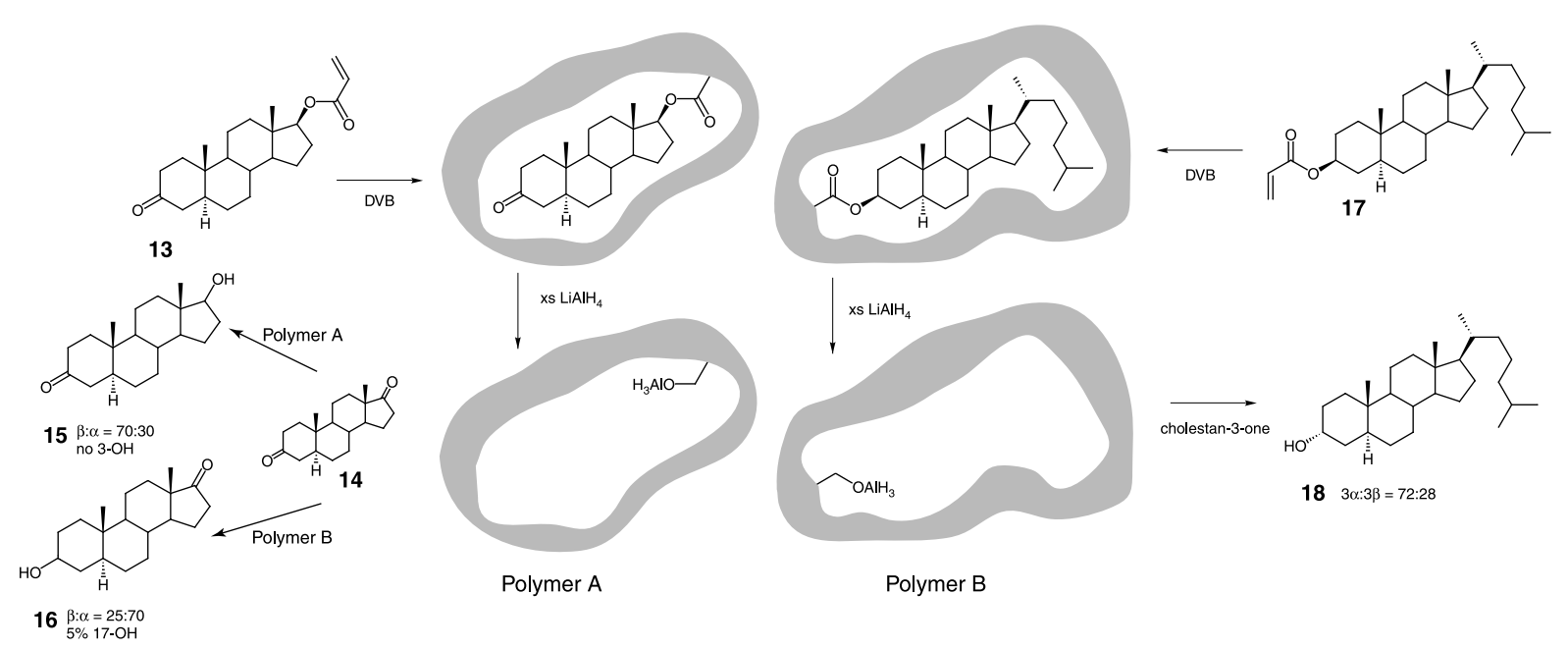

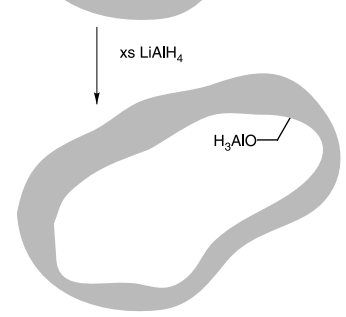

Polymer A

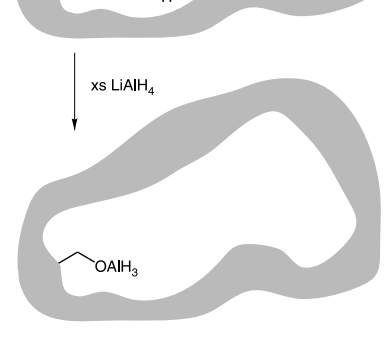

Polymer B

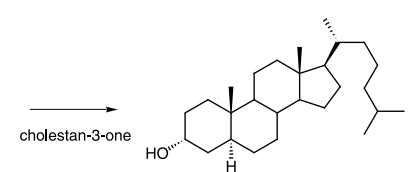

$183 \alpha: 3 \beta=72: 28$

Figure 6 Imprinted polymeric hydride reducing agents of Byström et al. ${ }^{22}$ Polymers were imprinted with sterol acrylate esters at either the $3 \beta$ or $17 \beta$ positions, templates (13) or (17) respectively. Reductive cleavage of the ester bond followed by treatment of the polymers with additional $\mathrm{LiAlH}_{4}$ immobilised the reactive groups at the former point of attachment of the sterol. The polymeric reagents were capable of both regio- and stereo-chemical control in the reduction of steroidal ketones (14) and cholestan-3-one.

from orientation not only of the attached glycine enolate, but also from coordination of the approaching acetaldehyde to electron-deficient boron in the polymer-bound boronic acid residues.

Wulff proposed that the incoming acetaldehyde was orientated at the $\mathrm{Si}$-face of the enolate, with the transition state constrained into an asymmetric conformation by the inherent chirality of the imprinted binding site. The possibility that enantioselective binding of the reaction products caused the observed ee was discounted by resolution experiments employing D,L-threonine: an $\alpha$-value of only 1.07 was observed compared to 1.64 for the template D,LDOPA, suggesting that it was indeed the specific orienta- tion of groups in the cavity which determined the stereochemistry of the reaction.

\section{$3 \quad$ Imprinted polymer supported reagents}

An ingenious use of imprinted polymer sites was published by Byström and co-workers ${ }^{22}$. Polymer beads were imprinted with sterols converted to acrylate esters at the 3and 17- positions. Removal of templates by reduction of the ester linkages, followed by reaction of the hydroxyl groups in the sites with excess $\mathrm{LiAlH}_{4}$, left hydride functionality specifically positioned in the cavities. The resultant polymer-supported reducing agents were then stirred 


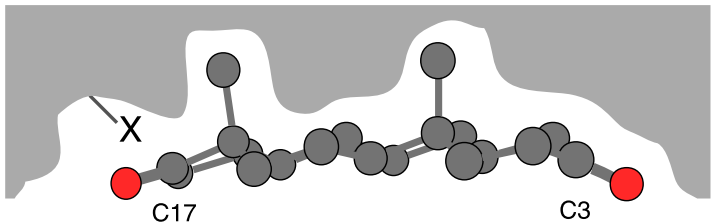

template matched to cavity: reagent $\mathrm{X}$ can approach $\mathrm{C} 17$

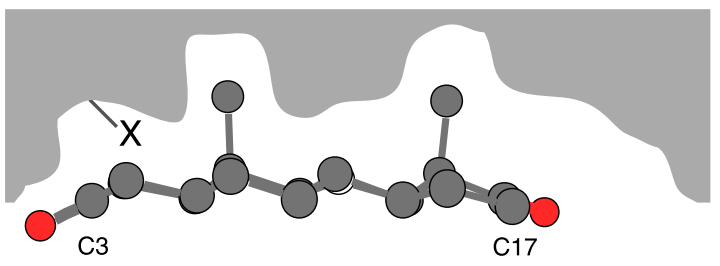

template mismatched to cavity: $\mathrm{X}$ cannot approach carbonyl group

Figure 7 The origin of regioselectivity in the reduction of androstan-3-17-dione (14) is the steric barrier formed by the imprint site which allows approach to the hydride group only when the ketone is oriented in the same way as the template.

with solutions containing androstan-3,17-dione, and cholestan-3-one (Figure 6).

Beads imprinted with the androstane-17-acrylate (13) reduced the diketone only at the 17- position, whereas in the absence of polymer there was almost complete preference for reduction at C-3. This is because under conventional solution conditions, approach of hydride takes place most readily at the less hindered 3-position, whereas the use of a sterically defined imprinted site allowed access of only the $\mathrm{C}-17$ carbonyl to the reducing agent, as shown in Figure 7.

Similarly, cholestane-3-acrylate imprinted polymers reduced androstane-3,17-dione to a far greater extent (85:15 ratio) at $\mathrm{C}-3$ compared to $\mathrm{C} 17$. This methodology also demonstrated stereochemical control, as polymers imprinted with cholestane-3-acrylate (17) reduced cholestane-3-one overridingly to the $3 \alpha$ - isomer $(\mathbf{1 8}, 72: 28$ ratio), whereas the same reduction chemistry in the absence of polymer yielded a 9 -fold excess of $3 \beta-\mathrm{OH}$ to $3 \alpha-$ $\mathrm{OH}$ (Figure 6).

The authors also referred to the influence of polymer "quality" on the results obtained. A low degree of swelling in the polymer matrix was essential to ensure the reduction of steroidal ketones occurred with the optimal regio- and stereoselectivity. Polymers prepared in "bulk" were inferior to those prepared as beads in a suspension polymerization in the absence of solvent. While these observations may be very specific to imprinted polymeric reagents which are relatively passive, these results imply that some attention must be given to the properties of the polymer scaffold as well as the reagent functionality.

\section{$4 \quad$ Imprinted polymers and protecting group strategies}

The use of polymers as protecting groups has long been established in synthetic chemistry, ${ }^{23}$ and thus protection strategies employing the stereochemically-defined binding sites of imprinted polymers have been increasingly investigated in recent years. For example, simply reacting D- or L-phenylalanine anilide with a fluorescent derivatization reagent, DNS-Cl (1-dimethylaminonaphthalene-5sulfonyl chloride) in the presence of a polymer imprinted with the L-isomer of the substrate resulted in $46 \%$ less Lderivative than $D .^{24}$ This example shows that binding to an imprinted polymer "protects" by limiting the availability of ligands for reaction in free solution. A fundamentally different approach is to direct the site of substitution by performing reactions on ligands bound stereoselectively to imprinted polymers.

We have been interested in determining whether imprinted polymers might be used as reusable protecting groups for the regioselective acylation of steroidal hydroxyl groups, as these compounds are of importance in physiology and medicine and because conventional solutionbased modification of these molecules is often extremely complex and time-consuming. Our studies centred on the acylation of di- and tri-hydroxysteroids bound to polymers imprinted with structurally related diols. ${ }^{25}$ Our initial work employed hydroxysteroids based on androst-5-ene $(\mathbf{1 9}, \mathbf{2 0}$, and 21), which were imprinted as esters with a polymerizable boronophthalide (22). Co-polymerization of these compounds with divinylbenzene in chloroform followed by template removal generated polymers $(\mathbf{2 3}, \mathbf{2 4}$, and 25) with either one or two points where hydroxyl groups could subsequently bind in the sites (Figure 8).

We then re-bound androst-5-ene-3 $\beta, 17 \beta$-diol (21) to each of the polymers $23, \mathbf{2 4}$ and 25 under dehydrating conditions. Formation of boronate esters with the hydroxyl groups of $\mathbf{2 1}$ should result in attachment of the steroid at the 3-position to polymer 23, at the 17-position on polymer $\mathbf{2 4}$, and at both 3 -and 17 -positions on polymer $\mathbf{2 5}$. We

Table 1 Modification of androst-5-ene-3 $\beta, 17 \beta$-diol (21) on Imprinted Polymers

\begin{tabular}{cccc}
\hline Polymer & Yield $^{\text {a }}$ of $\mathbf{2 1}(\mu$ moles $)$ & Yield $^{\text {a }}$ of Mono-acetates $(\mu$ moles $)$ & Ratio of Diol:Mono-Acetate \\
\hline $\mathbf{2 3}$ & 9.0 & 3.2 & $2.8: 1$ \\
$\mathbf{2 4}$ & 5.2 & 4.4 & $1.2: 1$ \\
$\mathbf{2 5}$ & 20.7 & 0.6 & $34.5: 1$ \\
\hline
\end{tabular}


<smiles>CC12CCCC1C1CC=C3C[C@H](O)CC[C@]3(C)C1CC2</smiles>

19

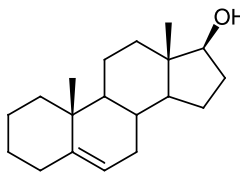

20

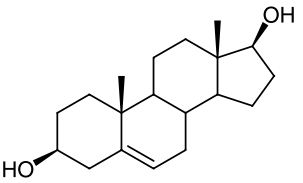

21

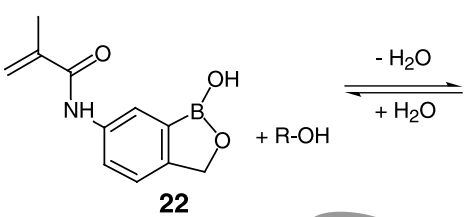

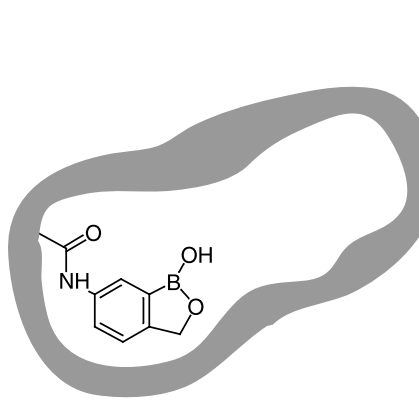

23

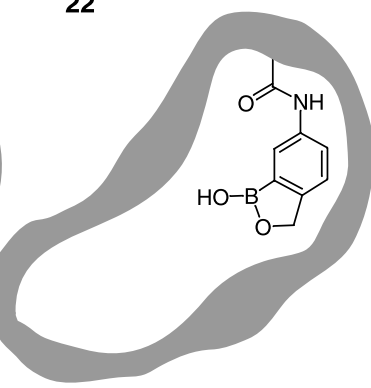

24<smiles>[R10]Cc1ccc(NC(=O)C(=C)C)cc1B1OCc2ccccc21</smiles>

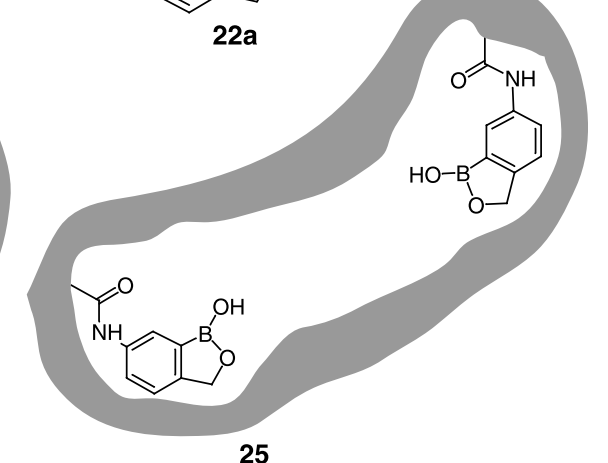

25

Figure 8 Androst-5-en-3 $\beta$-ol, (19), androst-5-en-17 $\beta$-ol (20) and androst-5-en-3 $\beta, 17 \beta$-diol (21), templates for the preparation of imprinted polymers bearing 3-methacrylamido-boronophthalide (22) residues. This monomer is capable of the covalent imprinting of alcohols with spatially separated hydroxyl groups via the boroate ester moiety (22a). Polymers 23, 24 and 25 represent the imprints of 19, 20 and 21 respectively.

subsequently washed the polymers with aprotic solvent to remove non-covalently attached steroid, and refluxed the polymer-steroid complexes with acetic anhydride and pyridine under conditions which would, in the absence of polymer, result in acetylation at both the 3- and 17-hydroxyl groups. After a further washing stage to remove any non-bound species, we recovered the reaction products via aqueous methanol hydrolysis. It is evident from the results shown in Table 1 that only polymer 25, which binds both the 3- and 17- positions, effectively protects both hydroxyl positions to the extent that less than $3 \%$ of the recovered material is monoester. The results also show that the capacity of this polymer is greater, with a recovery of $20.7 \mu \mathrm{mol}$ compared to $9 \mu \mathrm{mol}$ for the best recovery from a monohydroxysterol imprint.

We then refluxed polymer $\mathbf{2 5}$ with the trihydroxysteroid androst-5-ene-3 $\beta, 11 \beta, 17 \beta$-triol (26), and modification with acetic anhydride (Figure 9) was carried out. The hydrolytic solvent wash consisted of almost $90 \%$ of unmodified triol, however, the formation of a small amount (5$10 \%$ by integration) of the $11 \beta$-acetoxy derivative was deduced by NMR analysis. The low degree of reaction at the $11 \beta$-hydroxyl group in this case can be accounted for by the severe steric hindrance of the angular methyl groups at $\mathrm{C} 10$ and $\mathrm{C} 13$ and the fact that reagent access could only take place from the opposite face of the steroid which was very likely hindered by the polymer matrix. However, the ratio of $11 \beta$-acetoxy- to $3 \beta$-acetoxy products was at least $1: 1$ by integration and no evidence for modification at the $17 \beta$ position was obtained. This was in contrast to acety- lation of the same steroid in the absence of any polymer: in solution the $3 \beta, 17 \beta$-diacetate formed rapidly, whilst rather forcing conditions were required to achieve complete acylation of all three hydroxyl groups of 26. Although these results were promising, we concluded that a less-hindered steroid skeleton with more easily addressable functionality should be adopted to assess the practical feasibility of our approach.

We chose two accessible derivatives of cholic acid, t-butyldeoxycholate and t-butylchenodeoxycholate $(\mathbf{2 7}, \mathbf{2 8})$, as the template molecules, and imprinted these via their boronophthalide esters at the $3 \alpha-$ and $7 \alpha-$, or $3 \alpha-$ and $12 \alpha-$ positions respectively $(\mathbf{2 9}, \mathbf{3 0})$. The t-butyl ester group was used to protect the acid functionality on the templates thus preventing the formation of mixed boronic acid anhydrides at the imprinting stage, and also to provide steric bulk around which the polymer scaffolds $(\mathbf{3 1}, 32)$ were to be built. This we reasoned would ensure the creation of an extra pocket in the imprint site, to facilitate access of reagents to templates bound within the cavities. In this way, two "isomeric" polymers were produced, differing only in the position and orientation of boronophthalide groups in the imprint sites.

The next stage was to use these polymers as protective cavities for regioselective modification of hydroxysteroids. In particular, we were interested in finding out whether trihydroxysteroids based on deoxycholic acid and chenodeoxycholic acid would bind in the recognition sites in the same orientation as the templates with which polymers 31 and 32 were imprinted (i.e. by the $3 \alpha$ and $7 \alpha$ 


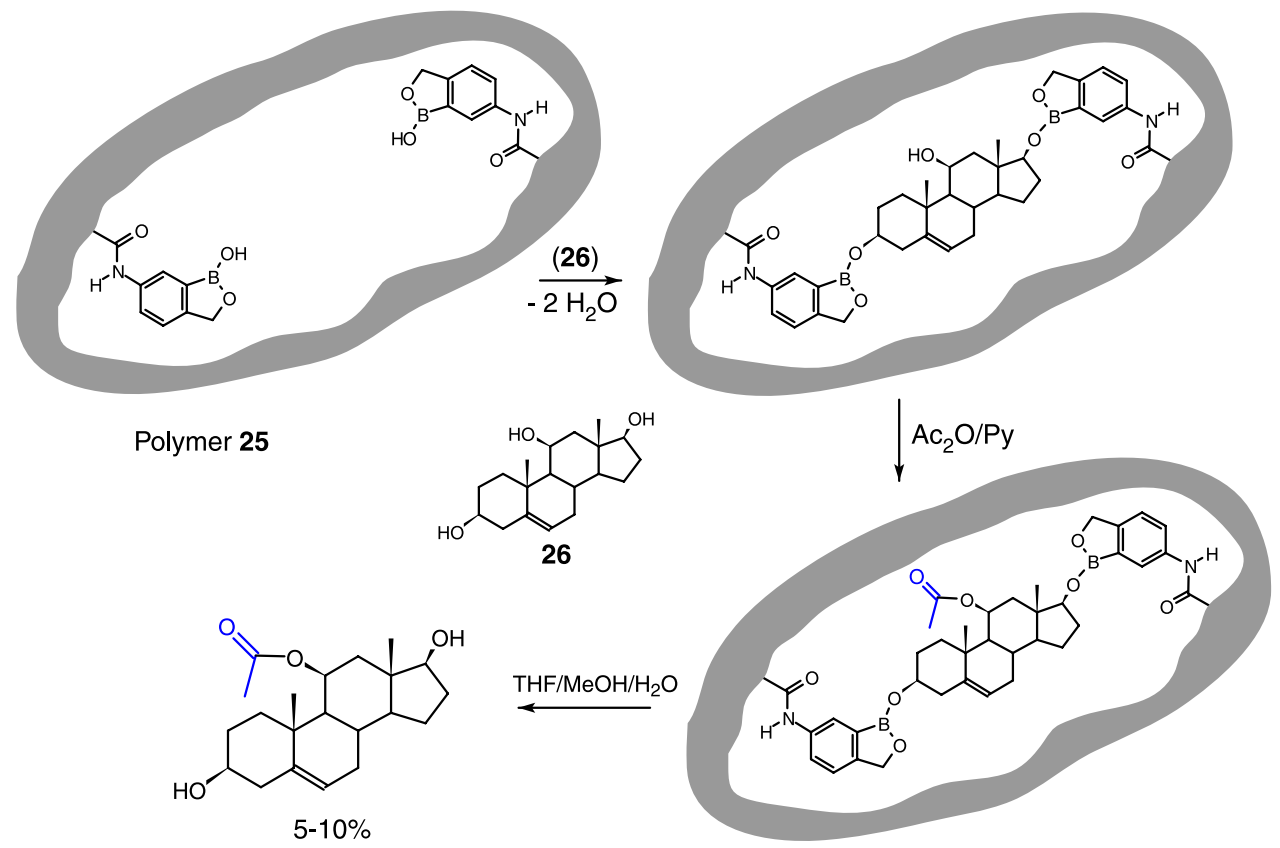

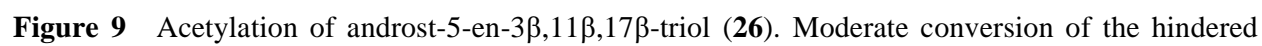
$11 \beta$-hydroxyl was seen despite the presence of the much more reactive $3 \beta$ - and $17 \beta-\mathrm{OH}$ groups which were protected by attachment to the polymer.

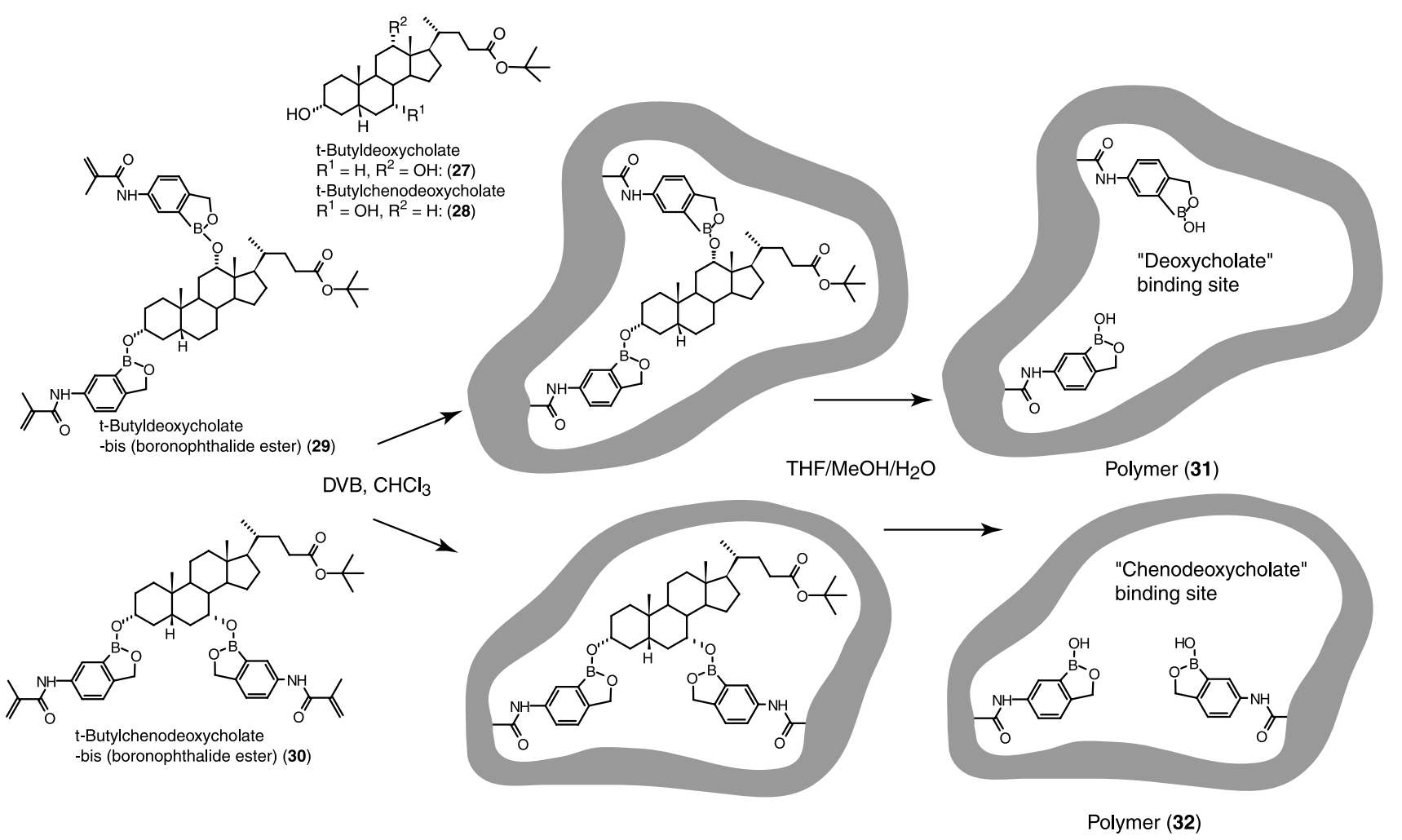

Figure 10 Formation of binding sites for regioselective sterol protection in polymers imprinted with t-butyldeoxycholate (27) and t-butylchenodeoxycholate (28), imprinted as their boronophthalide esters 29 and $\mathbf{3 0 .}$

or the $3 \alpha$ and $12 \alpha$ hydroxyls) leaving a residual hydroxyl group amenable to acetylation. The isomeric sterols $\mathbf{3 3}$ and 34 were prepared from deoxycholic acid and chenodeoxycholic acid respectively, with a view to establishing whether the polymers could discriminate between "matched" and "unmatched" template derivatives (Figures 10-12), and direct their regioselective acylation.

The results of these experiments are summarised in Table 2 which shows that when "matched" sterols are bound to 

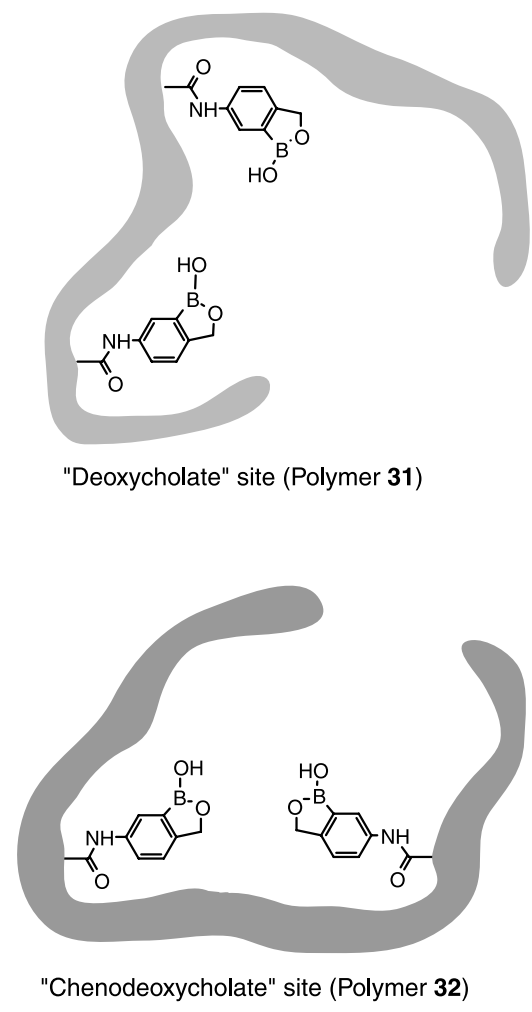
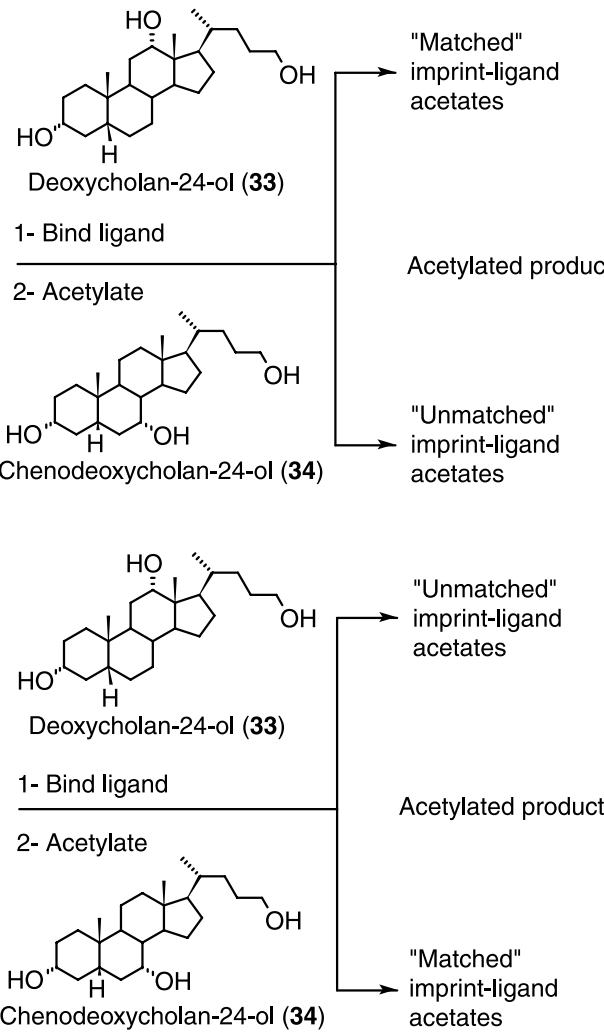

Figure 11 Binding of the trihydroxysterols 33 and $\mathbf{3 4}$ to polymers $\mathbf{3 1}$ and $\mathbf{3 2}$ and acetylation of the polymer-bound complexes should lead to the formation of acetylated products which reflect the orientation of the ligands in the binding sites.

Table 2 Modification of deoxycholan-24-ol (33) and chenodeoxycholan-24-ol (34) on imprinted polymers 31 and 32.

\begin{tabular}{ccccc}
\hline Polymer and ligand & Bound, $\boldsymbol{\mu \text { mol }}$ & Unmodified, $\%$ & Mono-acetates, $\%$ & Ratio 24-acetoxy:3-acetoxy \\
\hline $\mathbf{3 1}, \mathbf{3 3}$ (matched) & 29.0 & 36 & 64 & $10.5: 1$ \\
$\mathbf{3 2}, \mathbf{3 4}$ (matched) & 26.1 & 35 & 65 & $23.1: 1$ \\
$\mathbf{3 2}, \mathbf{3 3}$ (unmatched) & 25.5 & 49 & 51 & $5.4: 1$ \\
control $^{\mathbf{a}}, \mathbf{3 3}$ & 8.3 & 87 & 13 & $<1: 100$ \\
\hline
\end{tabular}

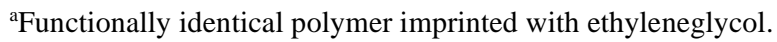

their corresponding polymers, acetylation at the 24-position is favoured by up 23.1:1, but this ratio falls to $5.4: 1$ in the case of the "umatched" ligand binding to the same polymer. This latter result probably indicates that binding to the 3-position is still more likely in this case, despite the prediction that an "unmatched" ligand would probably attach itself to the polymer non-specifically by the more reactive 24-hydroxyl (see Figure 12). When the same sterol was modified on a polymer imprinted with ethyleneglycol, there was almost complete acetylation at the $3 \alpha-\mathrm{OH}$, indicating that the sterol could attach only via its most accessible and reactive primary alcohol group at C-24. The presence of a sterol-derived cavity in the polymer was therefore responsible both for directing the regioselectivity of binding and the efficiency of the transformation.

\section{$5 \quad$ Catalysis}

Catalytic turnover has been demonstrated by a number of groups, who have generally adopted an approach analogous to the raising of catalytic antibodies, by imprinting polymers with a transition state analogue (TSA) for the reactions of interest. Robinson and Mosbach ${ }^{26}$ described the hydrolysis of 4-nitrophenylacetate (35) by a polymer imprinted with 4-nitrophenylmethylphosphonate (36) as an analogue of the tetrahedral transition state in the reaction pathway.

A related technique for the catalysis of a transesterification reaction on an inorganic support was reported by Heilmann and Maier, ${ }^{27}$ who imprinted a hydroxy-func- 


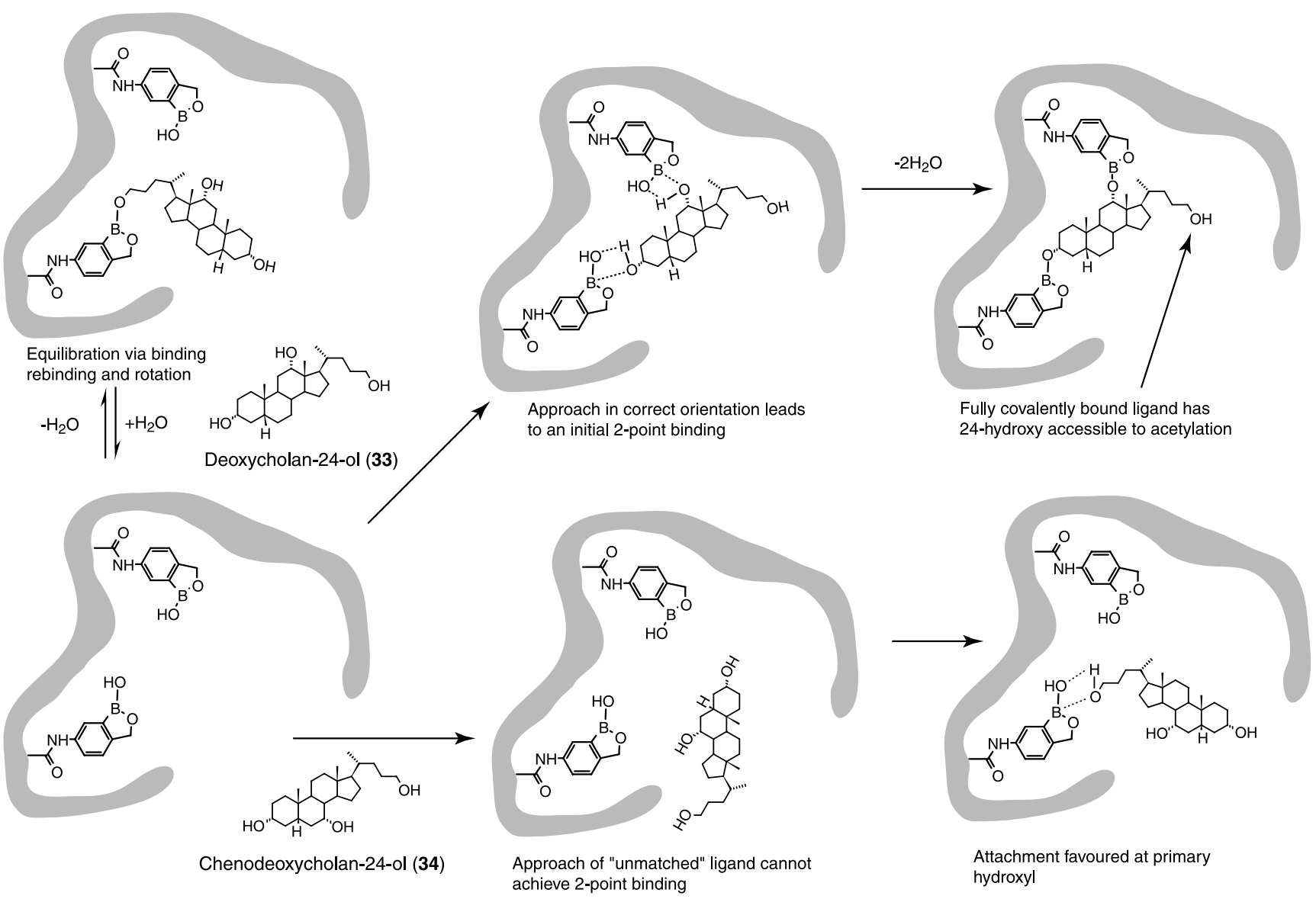

Figure 12 Binding of the ligand "matched" to the polymer binding site may require some equilibration until attachment in the correct orientation is achieved. There is evidence ${ }^{25}$ that the initial binding is non-covalent in nature, but following loss of water the doubly covalently-bound substrate can only be esterified at the $24-\mathrm{OH}$ position. The "unmatched" ligand can only bind non-specifically to the polymer and a different pattern of acetylation is predicted.

tional phosphonate (37) into silica. The imprint site in this case was produced by a sol-gel process via acid-catalysed decomposition of $\mathrm{Si}(\mathrm{OEt})_{4}$, with the transition state analogue bound to the silica matrix via a pendant benzylic hydroxyl group. The phosphonate ester was removed via pyrolysis at $250^{\circ} \mathrm{C}$, and the silica imprint sites were employed in transesterification reactions with n-hexanol, noctanol and $\alpha$-phenylethanol. The imprinted silica caused immediate catalytic turnover to a 1:1 mixture of hexyl and octylphenylacetate at a rate of $7 \mathrm{mmol} . \mathrm{h}^{-1}$, whereas a nonimprinted silica gave no detectable reaction within $48 \mathrm{hr}$.

A new approach to the synthesis of phosphonate ester-imprinted polymer catalysts was recently demonstrated by Wulff, ${ }^{28}$ who reasoned that since a complementary shape to a transition state analogue is not in itself sufficient to produce strong esterolytic activity, new functionality must be introduced into the polymer in order to improve the efficiency of catalysis. The indication that arginine residues play an important role in the catalytic mechanism of some antibodies raised against phosphonate ester haptens led Wulff and co-workers to investigate monomers bearing amidine functionality, which is the carbon analogue of the guanidine side group of arginine. The conse- quence of this investigation was the scheme illustrated in Figure 15, the monoaryl phosphonate (38) was imprinted with stoichiometric amounts of the amidine monomer

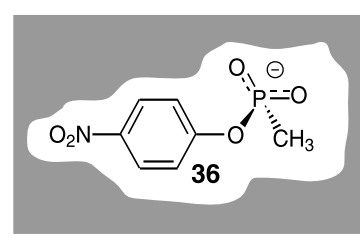

imprint transition state analogue

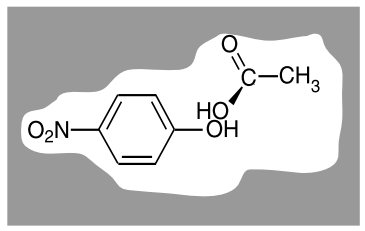

products

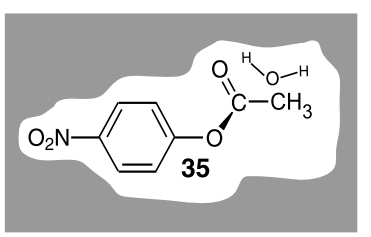

add reagents

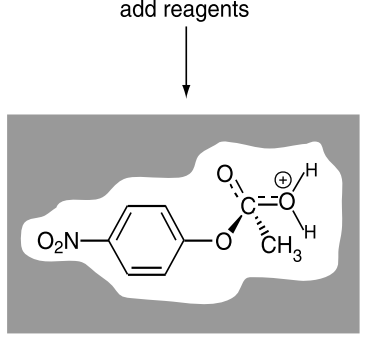

intermediate stabilised
Figure 13 Imprinting of a phosphonate ester transition state analogue (36) produces a polymer capable of catalysing the hydrolysis of the equivalent carboxylic ester (35). 


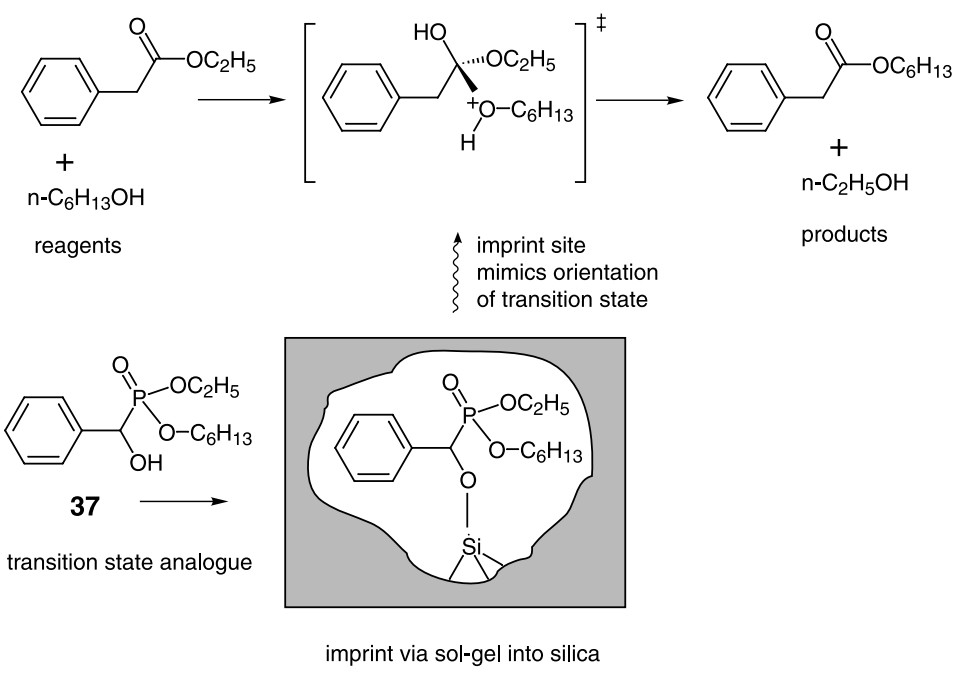

Figure 14 Transesterification on imprinted silica. ${ }^{27}$ The transition state analogue (37) bears both ethyl and hexyl ester functions and the resultant silica can catalyse the conversion of ethyl phenylacetate to the hexyl ester.

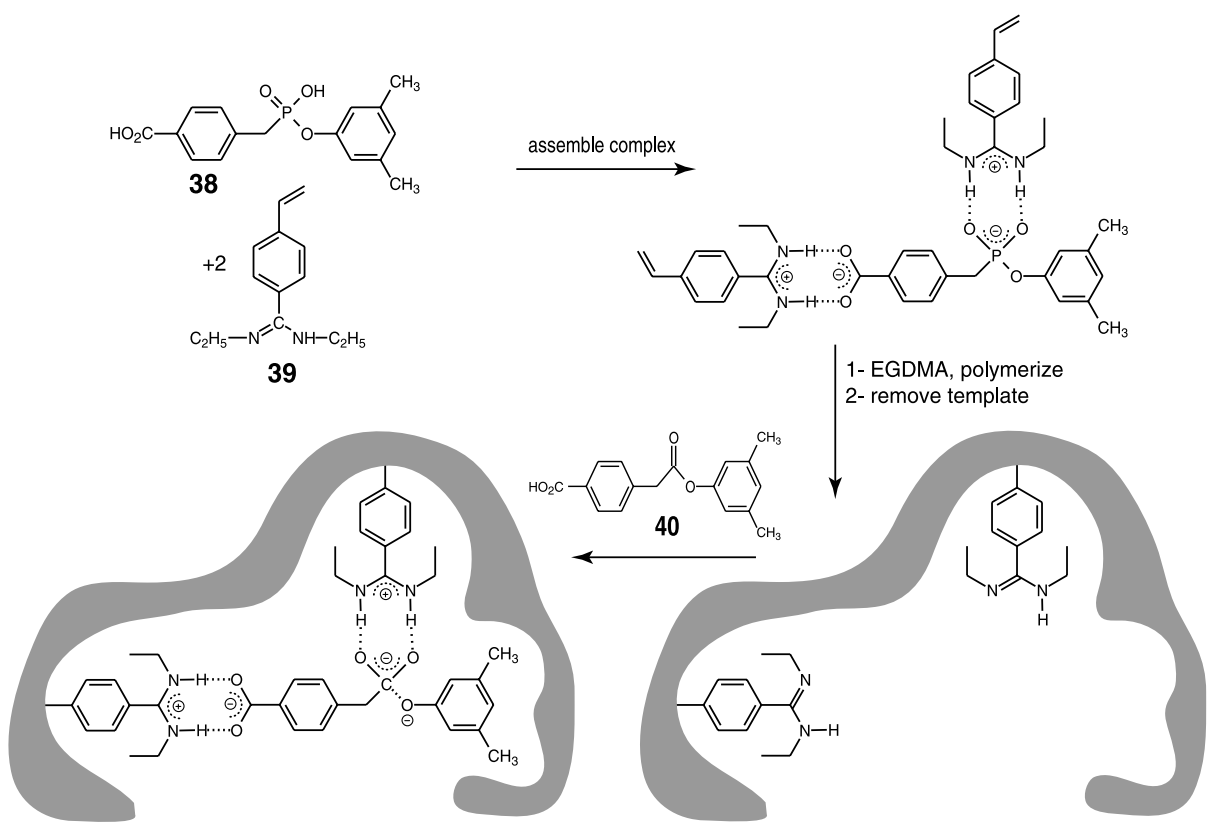

Figure 15 The polymers of Wulff ${ }^{28}$ showing strong esterase activity were prepared with the transition state analogue (38) and the new polymerizable amidine (39) which can be used in stoichiometric amounts in the imprinting step. The resultant polymers catalyse the alkaline hydrolysis of 40 with Michaelis-Menton kinetics.

(39), which has high association constants for both the carboxylic and phosphonic acid groups. The resulting polymer was shown to catalyse the alkaline hydrolysis of the carboxylic ester substrate (40) with Michaelis-Menton kinetics and a rate acceleration of more than 100-fold. Both the template (38) and the product of hydrolysis, homoterephthalic acid, are competitive inhibitors of catalysis and a relatively modest turnover was observed. Some substrate preference was also observed for polymers imprinted with two different aryl esters.
Catalytic imprints have not been confined to the preparation of hydrolytic enzyme analogues, for example Beach and Shea ${ }^{29}$ demonstrated the catalysis of the dehydrofluorination of 4-fluoro-4-nitrophenylbutan-2-one (41) by using a polymer imprinted with benzylmalonic acid (42) to orient $\mathrm{N}$-(2-aminoethy)-methacrylamide functional monomers in a co-polymer with methylmethacrylate and ethyleneglycoldimethacrylate (Figure 16a). Removal of the template left pendant amine groups in the polymer orientated to facilitate the $\beta$-elimination of HF. The same $\beta$ elimination was also the target for Müller et al. ${ }^{30}$ via non- 
A)
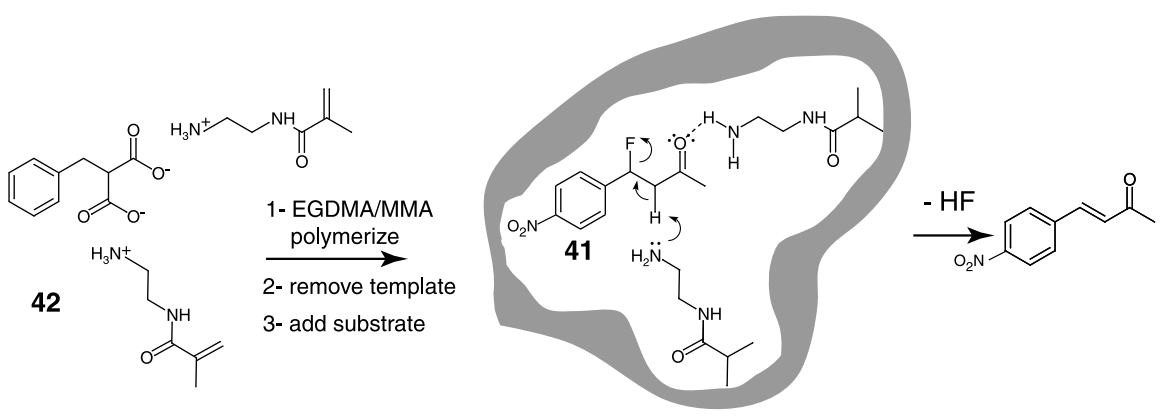

B)
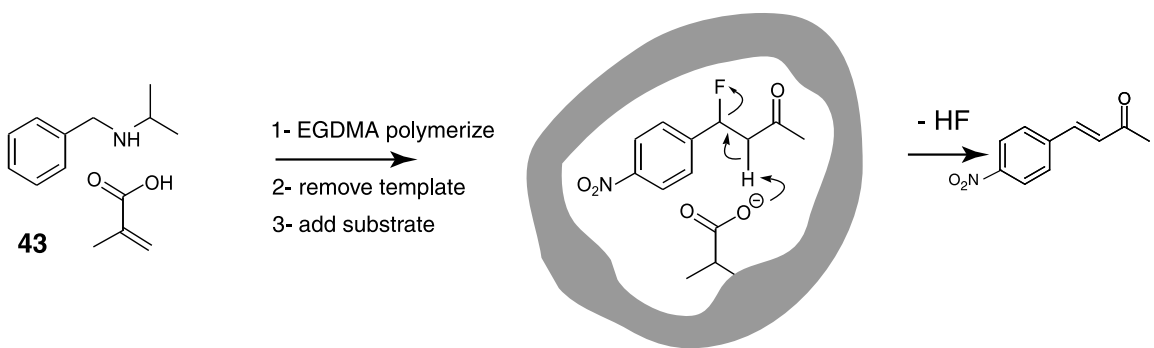

Figure 16 Imprinted catalysts for the dehydrofluorination of $\mathbf{4 1}$ have been prepared by two distinct routes. A) Beach and She ${ }^{29}$ used a malonic acid derivative (42) as the template, imprinting with basic functional monomers, whilst B) Müller et al. ${ }^{30}$ used the substituted benzylamine template (43), imprinted in the presence of methacrylic acid.

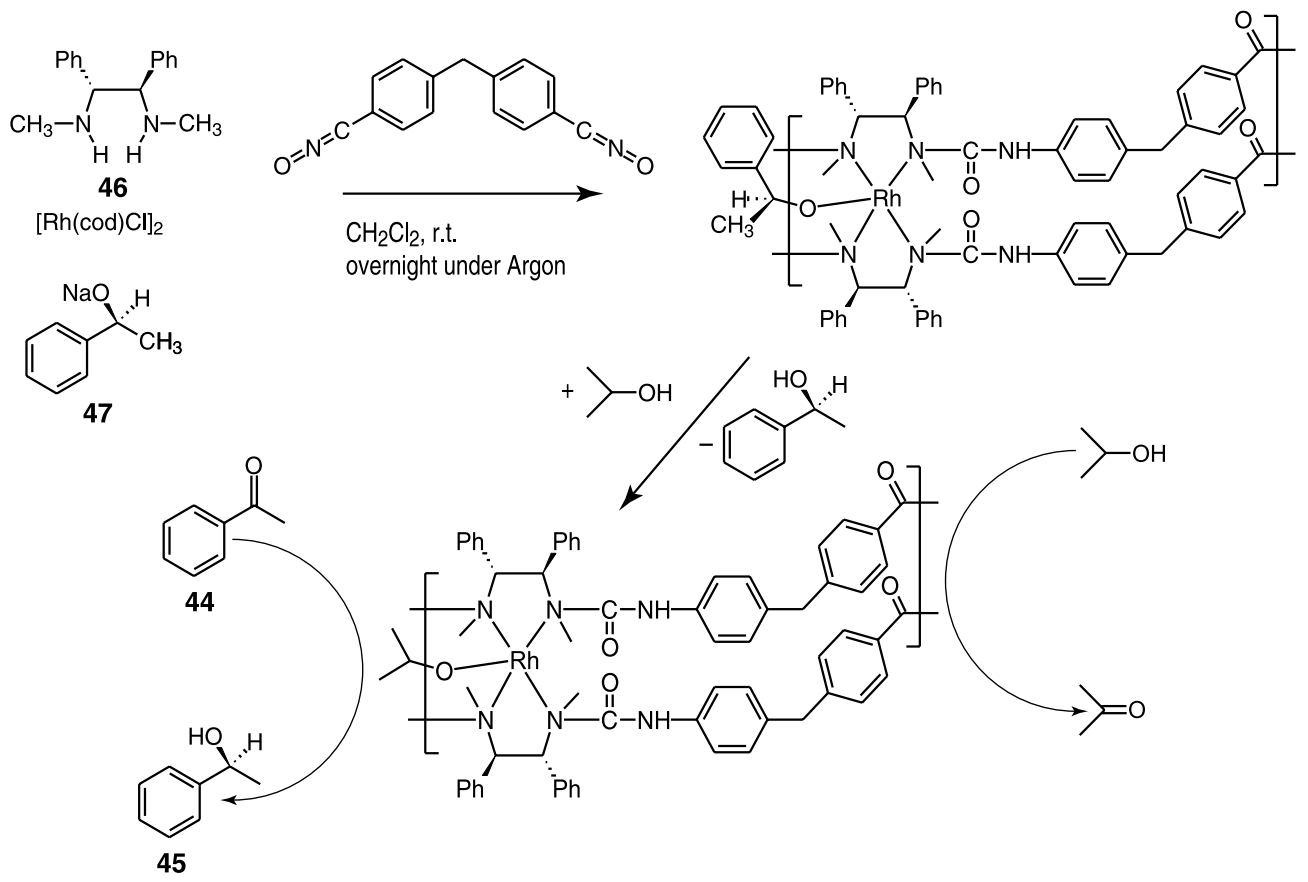

Figure 17 Imprinting with a chiral ligand in the preparation of heterogeneous rhodium hydride transfer catalyst can enhance the asymmetric induction over a non-templated catalyst. Cross-linking was achieved by using a mixture of di- and tri-isocyanates in the preparation of the metallated poly(carbamate) catalyst.

covalent imprinting method employing $N$-isopropylbenzylamine $(\mathbf{4 3})$ as the template with methacrylic acid as the functional monomer (Figure 16b). In this case the dehydrofluorination of $\mathbf{4 1}$ was catalysed by an orientated carboxyl group, with rate enhancements by a factor of 2.4 compared to the same reaction carried out in the presence of a polymer with randomly oriented carboxylates.
A different approach to the use of imprinted materials in catalysis has been pursued by the group of Lemarie ${ }^{31}$ who have been investigating the enantioselective hydride transfer reaction at a catalytic rhodium complex. The intrinsically chiral complex catalyses the enantioselective reduction of acetophenone (44) in the presence of isopropanol (Figure 17). The chirality of the product 1-phenyl- 
Table 3 Some examples of imprinted catalysts found in the literature.

\begin{tabular}{|c|c|c|}
\hline Reference & Catalytic reaction & Description \\
\hline 36 & & $\begin{array}{l}\text { Revicw of rational catalyst design via imprinted } \\
\text { nanostructured materials }\end{array}$ \\
\hline 37 & & $\begin{array}{l}\text { Short review of synthesis and catalysis by molecularly } \\
\text { imprinted materials }\end{array}$ \\
\hline $2 \overline{2}$ & Transesterification of ethyl phenylacetate with hexanol & Imprinting of phosphonate ester $\mathrm{TSA}$ in silica gel \\
\hline 38 & Butanolysis of benzoic anhydride & $\begin{array}{l}\text { "Footprint" catalysts formed on the surface Al-Si hybrid } \\
\text { gels }\end{array}$ \\
\hline 39 & $\begin{array}{l}\text { Enantioselective dinitrophenolysis of benzoic } N- \\
\text { benzyloxycarbonyl-alanine anhydride }\end{array}$ & $\begin{array}{l}\text { "Footprint" catalysts formed on the surface Al-Si hybrid } \\
\text { gels }\end{array}$ \\
\hline 26 & Hydrolysis of $p$-nitrophenyl acetate & $\begin{array}{l}\mathrm{Co} \text { mediated imprinting of a TSA, network fromed by } \\
\text { crosslinking of poly(vinylimidazole) }\end{array}$ \\
\hline 40 & Hydrolysis of p-nitrophenyl ester & $\begin{array}{l}\text { TSA Co } \\
\text { linear polymers }\end{array}$ \\
\hline 41 & Hydrolysis of p-nitrophenyl ester & $\begin{array}{l}\text { "Water soluble" acrylamide based polymer imprinted with a } \\
\text { TSA }\end{array}$ \\
\hline 32 & Enantioselective ester hydrolysis & $\begin{array}{l}\text { Catalytic groups arranged by a combination of covalent and } \\
\text { no-covalent imprinting strategies }\end{array}$ \\
\hline 20 & Hydrolysis of p-nitrophenyl ester & $\begin{array}{l}\mathrm{Co} \text { mediated imprinting of a TSA in vinylimidazole/DVB } \\
\text { copolymer }\end{array}$ \\
\hline 42 & "Chymotrypsin-like" hydrolysis of p-nitrophenyl ester & $\begin{array}{l}\mathrm{Co}{ }^{2+} \text { mediated imprinting of a TSA using a "triad" of } \\
\text { functional monomers }\end{array}$ \\
\hline 43 & Hydrolysis of nitrophenyl acetate & $\begin{array}{l}\text { Non-covalent imprinting of TSA in a vinylimidazole /DVB } \\
\text { polymer }\end{array}$ \\
\hline 44 & "Biocatalyst-like" hydrolysis of p-nitrophenyl ester & $\mathrm{Co}{ }^{2+}$ mediated surface imprint \\
\hline 28 & Hydrolysis of alkylated phenyl esters & $\begin{array}{l}\text { Stoichiometric non-covalent imprinting of TSA with an } \\
\text { amidine functional monomer }\end{array}$ \\
\hline 29 & $\begin{array}{l}\text { Dehydrofluorination of } 4 \text {-fluoro-4-(p-nitrophenyl)butan-2- } \\
\text { one }\end{array}$ & Non-covalent imprinting with a basic functional monomer \\
\hline 30 & $\begin{array}{l}\text { Dehydrofluorination of } 4 \text {-fluoro-4-(p-nitrophenyl)butan-2- } \\
\text { one }\end{array}$ & Non-covalent imprinting with an acidic functional monomer \\
\hline 33 & Diels-Alder & Non-covalent imprinting of product analogue \\
\hline$-\overline{35}$ & Class II aldolase mimic & $\mathrm{Co}^{2+}$ mediated imprinting of 1,3 diketones \\
\hline 34 & Benzisoxazole isomerization & Non-covalent imprinting of substrate analogue \\
\hline 31 & Enantioselective hydride transfer to aryl ketones & Templated Rh complex in a polyurethane matrix. \\
\hline
\end{tabular}

ethanol (45) is determined by the configuration of the chiral diamine ligand (46), however the enantiomeric excess (ee) of the product alcohols is modest (25-33\%) compared to that achievable with an equivalent homogeneous catalyst (up to 67\%). By contrast, preparing the same heterogeneous catalyst in the presence of a template ligand (47) derived from chiral 1-phenylethanol resulted in a polymer catalyst with enhanced enantioselectivity, approaching that of the homogeneous reaction. In fact with careful control of the cross-linking ratio (mixture of triand di-isocyanates) a polymer was prepared which catal- ysed the production of $(R)-1$-phenylethanol with an ee of $70 \%$, exceeding the value for the homogeneous catalysis. The above, along with some other examples of imprinted polymer catalysts, are summarised in Table 3. Notable examples are: polymers catalysing enantioselective ester hydrolysis, prepared by a combination of covalent and noncovalent imprinting strategies to position functionality in the catalytic site $^{32}$ and the preparation of polymers to catalyse a Diels-Alder reaction, ${ }^{33}$ the isomerization of benzisoxazole ${ }^{34}$ and as a class II aldolase mimic. ${ }^{35}$ 
6

\section{Future Prospects}

Clearly the use of imprinted materials in chemistry is in its infancy but the potential for exciting future developments has been amply demonstrated. In the area of polymers as protecting groups and "microreactors" there are still problems to be solved concerning the accessibility of sites and the retention of their stereochemical memory. Perhaps the development of "surface-imprinting" techniques, new functional monomers and imprinting matrices would help to address these issues.

The manufacture of specific and efficient imprinted catalysts still remains something of a "Holy Grail" for many scientists working in the area. While much of the early work has focused on enzyme models and the results of catalytic antibody research, the incorporation of catalytic centres based on transition metals into imprinted material have hitherto largely been ignored. New developments such as this will require insight into both reaction mechanisms and interfacial processes and would probably involve collaboration between groups traditionally working in very different areas of chemistry.

\section{References and Notes}

* Current address: School of Pharmacy and Biomedical Sciences, University of Portsmouth, St Michael's Building, White Swan Road, Portsmouth PO1 2DT UK.

(1) Vulfson, E. N.; Alexander, C.; Whitcombe, M. J. Chem. Br. 1997, 33, 23.

(2) Mosbach, K. Trends Biochem. Sci. 1994, 19, 9.

(3) Mosbach, K.; Ramström, O. Bio/Technology 1996, 14, 163.

(4) Mosbach, K.; Haupt, K. Journal Of Molecular Recognition 1998, 11,62 .

(5) Ramström, O.; Ansell, R. J. Chirality 1998, 10, 195.

(6) Shea, K. J. Trends Polym. Sci. 1994, 2, 166.

(7) Steinke, J.; Sherrington, D. C.; Dunkin, I. R. Adv. Polym. Sci. 1995, 123, 81.

(8) Vidyasankar, S.; Arnold, F. H. Curr. Opinion Biotech. 1995, 6, 218.

(9) Wulff, G. Angew. Chem., Intl. Ed. Engl. 1995, 34, 1812.

(10) Molecular and Ionic Recognition with Imprinted Polymers, ACS Symp. Ser. 703; Bartsch, R. A.; Maeda M., Eds.; ACS: Washington DC, 1998.

(11) See also The Society for Molecular Imprinting web site: http:/ /www.ng.hik.se/ SMI/

(12) Kempe, M.; Mosbach, K. J. Chromatogr. A 1994, 664, 276. Kempe, M.; Mosbach, K. J. Chromatogr. A 1995, 691, 317. Kempe, M.; Mosbach, K. J. Chromatogr. A 1995, 694, 3.

(13) Ramström, O.; Yu, C.; Mosbach, K. Journal Of Molecular Recognition 1996, 9, 691. Ramström, O.; Ye, L.; Gustavsson, P. E. Chromatographia 1998, 48, 197.

(14) Adbo, K.; Andersson, H. S.; Ankarloo, J.; Karlsson, J. G.; Norell, M. C.; Olofsson, L.; Svenson, J.; Ortegren, U.; Nicholls, I. A. Bioorganic Chemistry 1999, 27, 363.

(15) Vlatakis, G.; Andersson, L. I.; Müller, R.; Mosbach, K. Nature 1993, 361, 645.

(16) Ramström, O.; Ye, L.; Mosbach, K. Chemistry \& Biology 1996, 3,471 .
(17) Shea, K. J.; Thompson, E. A.; Pandey, S. D.; Beauchamp, P. S. J. Am. Chem. Soc. 1980, 102, 3149.

(18) Damen, J.; Neckers, D. C. J. Am. Chem. Soc. 1980, 102, 3265.

(19) Sarhan, A.; Abou El-Zahab, M. Makromol. Chem. Rapid Commun. 1987, 8, 555.

(20) Leonhardt, A.; Mosbach, K. React. Polym. Ion Exch., Sorbents 1987, 6, 285.

(21) Wulff, G. In Polymeric Reagents and Catalysts. ACS Symp. Ser. 308; Ford, W. T. Ed.; ACS: Washinton DC, 1986; p186. Wulff, G.; Vietmeier, J. Makromol. Chem. 1989, 190, 1717. Wulff, G.; Vietmeier, J. Makromol. Chem. 1989, 190, 1727.

(22) Byström, S. E.; Borje, A.; Akermark, B. J. Am. Chem. Soc. 1993, 115, 2081.

(23) Hodge, P. In Syntheses and Separations Using Functional Polymers; Sherrington, D. C.; Hodge, P., Eds.; John Wiley \& Sons: $1988 ; \mathrm{p} 43$.

(24) Hamase, K.; Iwashita, K.; Zaitsu, K. Anal. Sci. 1999, 15, 411.

(25) Alexander, C.; Smith, C. R.; Whitcombe, M. J.; Vulfson, E. N. J. Am. Chem. Soc. 1999, 121, 6640.

(26) Robinson, D. K.; Mosbach, K. J. Chem. Soc., Chem. Commun. 1989, 969.

(27) Heilmann, J.; Maier, W. F. Angew. Chem., Intl. Ed. Engl. 1994, 33, 471.

(28) Wulff, G.; Gross, T.; Schönfeld, R. Angew. Chem., Intl. Ed. Engl. 1997, 36, 1962.

(29) Beach, J. V.; Shea, K. J. J. Am. Chem. Soc. 1994, 116, 379.

(30) Müller, R.; Andersson, L. I.; Mosbach, K. Makromol. Chem. Rapid Commun. 1993, 14, 637.

(31) Gamez, P.; Dunjic, B.; Pinel, C.; Lemaire, M. Tetrahedron Lett. 1995, 36, 8779. Locatelli, F.; Gamez, P.; Lemaire, M. J. Mol. Cat. A 1998, 135, 89.

(32) Sellergren, B.; Shea, K. J. Tet.-Asym. 1994, 5, 1403.

(33) Liu, X. C.; Mosbach, K. Macromol. Rapid Commun. 1997, 18 , 609.

(34) Liu, X. C.; Mosbach, K. Macromol. Rapid Commun. 1998, 19 , 671.

(35) Matsui, J.; Nicholls, I. A.; Karube, I.; Mosbach, K. J. Org. Chem. 1996, 61, 5414.

(36) Davis, M. E.; Katz, A.; Ahmad, W. R. Chem. Mater. 1996, 8, 1820.

(37) Ramström, O.; Mosbach, K. Curr. Opinion Chem. Biol. 1999, 3,759 .

(38) Morihara, K.; Kurihara, S.; Suzuki, J. Bull. Chem. Soc. Jpn. 1988, 61, 3991.

(39) Morihara, K.; Kurokawa, M.; Kamata, Y.; Shimada, T. J. Chem. Soc. ,Chem. Commun. 1992, 358.

(40) Ohkubo, K.; Urata, Y.; Honda, Y.; Nakashima, Y.; Yoshinaga, K. Polymer 1994, 35, 5372.

(41) Ohkubo, K.; Funakoshi, Y.; Urata, Y.; Hirota, S.; Usui, S.; Sagawa, T. J. Chem. Soc., Chem. Commun. 1995, 2143.

(42) Karmalkar, R. N.; Kulkarni, M. G.; Mashelkar, R. A. Macromolecules 1996, 29, 1366. Lele, B. S.; Kulkarni, M. G.; Mashelkar, R. A. Reactive \& Functional Polymers 1999, 39, 37. Lele, B. S.; Kulkarni, M. G.; Mashelkar, R. A. Reactive \& Functional Polymers 1999, 40, 215.

(43) Kawanami, Y.; Yunoki, T.; Nakamura, A.; Fujii, K.; Umano, K.; Yamauchi, H.; Masuda, K. J. Mol. Cat. A 1999, 145, 107.

(44) Toorisaka, E.; Yoshida, M.; Uezu, K.; Goto, M.; Furusaki, S. Chem. Lett. 1999, 387.

Article Identifier:

1437-2096,E;2000,0,06,0911,0923,ftx,en;T01200ST.pdf 